\title{
An Overview of Pollination in Rangelands: Who, Why, and How
}

\section{By Jason P. Harmon, Amy C. Ganguli, and Michelle J. Solga}

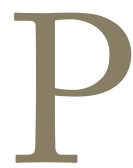
ollination is one of the most well-known relationships that can occur between two species. Most of us are told at a very early age that bee pollination of flowers is a mutualism, and that mutualisms occur when two species "work together for a mutual benefit." This feel-good, iconic image of nature permeates our impression of how this important interaction works, but, in doing so, it distorts the complexity of how and why numerous plant species interact with a diverse array of pollinators.

To understand pollination in rangeland systems, we need to realize that our concept of mutualisms is usually anthropomorphized. That is, we take human ideas of cooperation and self-sacrifice to describe plants and animal pollinators interacting. Although both plants and pollinators do usually benefit, pollination is not a purposefully unselfish or altruistic relationship. It is probably more accurate to think about pollination as a complex ecological negotiation for desired services. Flowering plants want to attract pollinators and "bribe" them into working for the plant. Meanwhile, numerous potential pollinators try to acquire food and other resources from plants however they can. This alternative viewpoint may help us better understand why plants and pollinators bother interacting with each other and how exactly that interaction works.

In this article we present a brief overview of pollination by using examples and species relevant to rangelands. Our primary goal in providing this background information is to display some of the fascinating richness of plant-pollinator interactions. We hope that doing so will prepare and encourage you to read the subsequent articles to learn about the challenges facing pollinators in rangelands and what we can do about them. In this article we first touch on how plants reproduce and why they use animals to help them. Next, we look at the rewards plants provide pollinators. We then briefly survey the diverse assemblage of animal pollinators found in rangeland habitats. We conclude with a discussion about the nature of pollination interactions, including some complicated associations.

\section{Plant Reproduction-Why Do Plants Pay for Service? \\ How Plants Reproduce and the Benefits of Pollination by Animals}

New plants are created in a variety of different ways. Although plants can produce new individuals asexually, sexual reproduction is required for plants to combine genetic information. For this to occur, pollen from the male part of a plant must come in contact with the female part of a plant of the same species.

The question then is how the plant moves that pollen. For many, the solution is to bribe an animal. Approximately three-quarters of all existing flowering plants engage in some level of plant-pollinator interaction. ${ }^{1}$ Plant-pollinator interactions have traditionally been underappreciated in rangelands because the dominant species in these ecosystems are typically wind-pollinated (e.g., plants in the Poaceae, Cyperaceae, Chenopodeaceae, Polygonaceae). Other plants do not move pollen much at all, and are instead self-pollinated such that pollen from one flower fertilizes another flower from the same individual plant or the same flower includes both male and female parts. Wind- or self-pollinated plants, including most grasses (Fig. 1), occur in large populations and typically transport pollen over relatively short distances. Advantages of this reproductive strategy include the ability to reproduce without relying on pollinators and conservation of energy because fewer resources are invested in attracting pollinators. Disadvantages of this reproduction strategy include reduced genetic diversity through reduced instances of outcrossing when compared to animal-pollinated species. In other words, wind-pollinated plants do not exchange as much genetic material with genetically different individuals, and this can ultimately hurt the plant population. Animalpollinated plants have the advantage of increasing genetic diversity within a plant population through increasing the genetic diversity of their offspring. This is particularly important in the maintenance of rare and endangered plant species (see Travers et al., this issue). However, if animal 


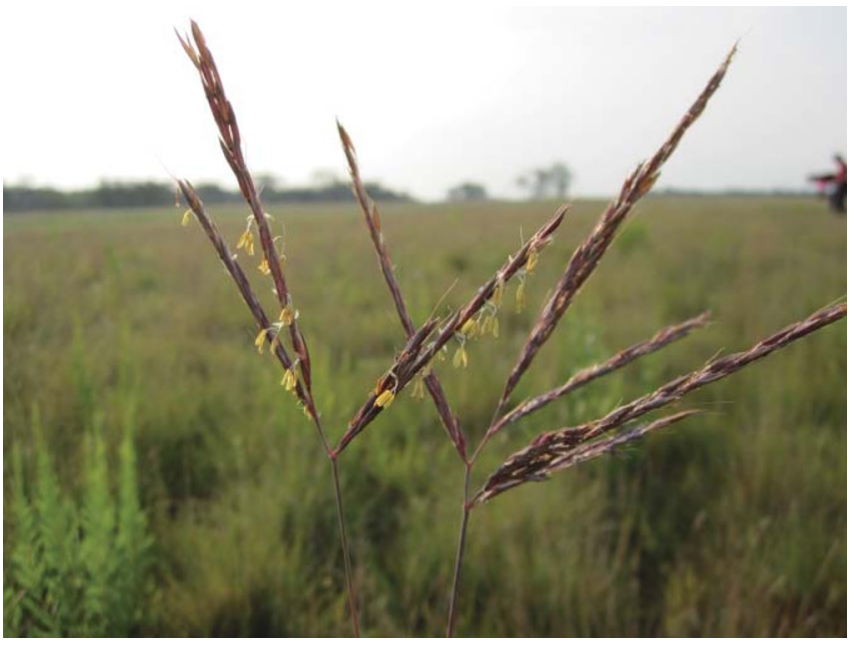

Figure 1. Big bluestem is an example of a common wind-pollinated rangelands plant. Despite not needing animal pollinators for reproduction, the pollen from wind-pollinated plants may sometimes be used by bees and other pollinators.

pollinators are not present plants can have poor reproductive success because they produce fewer seeds when they receive less pollen. ${ }^{2}$ This means that the level of pollination, for good or for bad, impacts plant population and community dynamics by altering plant abundance, population viability, and floral traits. ${ }^{2}$

\section{Ecosystem Services Provided by Pollination}

Pollinators play a critical role in maintaining ecosystem structure and function by providing the pollination services required for many plant species to reproduce. In addition, animal-pollinated plant species produce food for wildlife in the form of seeds and fruits. Pollinators themselves (e.g., beetles, ants, flies, butterflies, and moths) also provide an important food source for many wildlife species (e.g., sage grouse, black bears, grizzly bears, and a variety of songbird species). Plant species that need pollinators also help create healthy and vibrant habitats for recreational opportunities in rangelands including hiking, birding, and hunting. Pollination-derived ecosystem services are further discussed in Gilgert and Vaughn (this issue). The ecosystem services provided by pollination are far reaching and an important part of the goods and services derived from rangeland ecosystems worldwide.

\section{Resources for Pollinators-What Is in It for the Pollinators?}

Pollinators don't help plants out of the goodness of their simple circulatory systems. Pollinators expect to be paid for their work. Here, we discuss the primary forms of payment plants offer to entice, reward, and train pollinators to help with plant reproduction.

Pollen

Some 400 million years ago pollen was used as the first food reward plants offered as "payment" for reproduction-related dispersal. ${ }^{3}$ Because pollen is an important part of plant reproduction, plants are already making this nutritive-rich substance and it can be offered as a reward without the plant creating any new, specialized structures that are used just for interacting with pollinators. ${ }^{4}$

Pollen may seem like the most abundant pollinator reward (just ask anyone with pollen allergies), but of all the potential animal pollinators in the world, relatively few can digest pollen. ${ }^{4}$ However, it is used by many insects that pollinate rangeland plants. ${ }^{3}$ For example, most bees collect it and use it to feed their young. Adult syrphids (flower flies) and some butterflies eat the grains themselves, and other insects such as thrips puncture pollen grains so they can suck up the contents.

Pollen is an extremely nutritious food source that contains protein and "essential" amino acids along with lipids, carbohydrates, minerals, enzymes, oils, and pigments., However, just as different plants contain different nutrients for herbivores, pollen from different plants contains different nutrients. For instance, some pollen grains are rich in starch, others in lipids. There may be some relationship between nutritive content and how the plant is pollinated, but there are no simple relationships between a plant species, its pollen, and its pollinators.

Just because some plant species use pollen as a reward does not mean that all plants need or even want pollinators to take their pollen. Insects that can take and use pollen for themselves will do so when it benefits them regardless of the plant's interests. Scientists have traditionally thought that some insects visit wind-pollinated plants to "steal" their pollen without benefitting the plant. ${ }^{5}$ Numerous examples show insect pollinators visiting wind-pollinated plants and using their pollen; however, the exact relationship between plant and pollinator is less straightforward. Sometimes insects are clearly swiping pollen with no benefit to the plant. Honeybees, for example, collect pollen from the tassels of maize (corn) without visiting the silks where pollen is needed for germination. In other cases, insect visitation does benefit the plant. Solitary bees (Halictidae) actively collect pollen from a temperate grass species and the combination of bees and wind increase seed set in that grass compared to wind pollination alone. Since some insect pollinators use pollen from grasses and other wind-pollinated plants, traditional rangeland grasses could help insect pollinators and the other plants that do use those pollinators.

\section{Nectar}

Nectar is the most common reward for pollinators and it is used by representatives from almost all known pollinator groups. ${ }^{4}$ Unlike pollen, nectar is not directly related to plant reproduction, but instead is produced through a complicated physiological process specifically for potential pollinators. Since nectar is produced explicitly for pollinators there is often a tight, coevolutionary relationship between the plant's nectar and the plant's potential pollinators. ${ }^{4}$ 


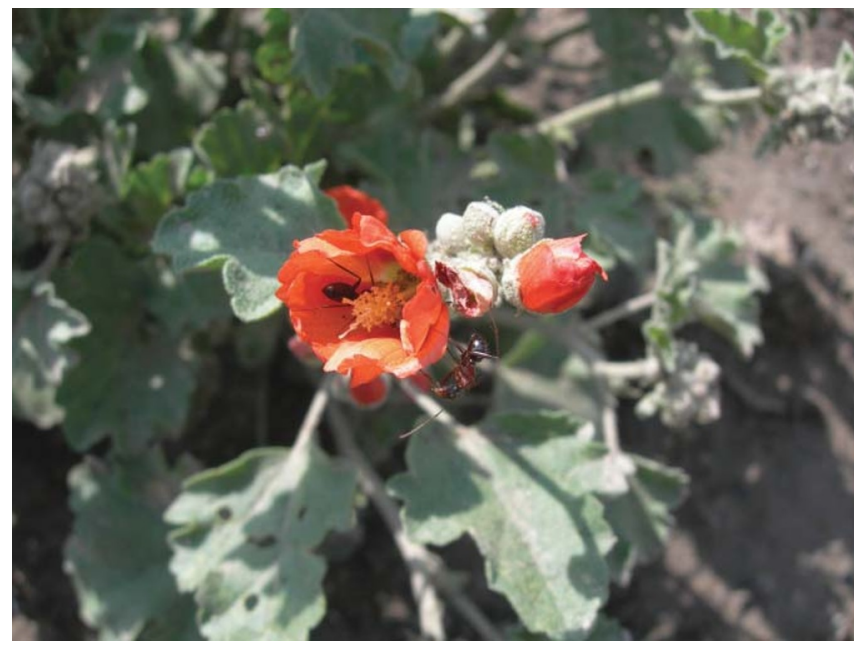

Figure 2. Munro's globemallow is a flowering rangelands plant that is pollinated by insects such as bees and is visited by many more insects including ants.

This tight correlation can be seen in the nectar's content. Nectar is predominately sugar in a water-based solution, but the types of sugars, their relative concentration, and the amount of nectar produced can all vary considerably., Remember that plants do not want a pollinator to visit one flower, drink its fill, and leave. Successful pollination requires a pollinator to visit multiple flowers of the same plant species. Therefore, the plant must strike a delicate balance. Producing lots of nectar costs the plant energy and resources and may result in too few pollinator visits. However, not producing enough nutritious nectar may keep pollinators from being able to fly or reproduce and cause them to go search for better resources.

Nectar isn't all sugar water. It also contains amino acids, proteins, lipids, organic acids, phenolics, alkaloids, terpenoids, and more. Because of the tight connection between nectar and pollinators, each component probably has some relationship to pollination. Similarly, variation in when nectar is produced and how plants allow access to nectar are usually correlated with potential pollinators.

Despite the strong correlation between nectar and pollinators, some animals obtain nectar without pollinating the plant by performing "floral larceny." "Thieves" such as ants and other small insects take nectar through the normal route without actually pollinating (Fig. 2). "Nectar robbers" obtain nectar by chewing a hole or piercing through flower parts. These holes can be used by later, secondary robbers. Although taking nectar without pollinating can negatively affect the plant, in some cases these robbers alter the behavior of real pollinators in a way that ultimately benefits the robbed plant. $^{6}$

Animals aren't the only ones manipulating the situation to their own advantage. Besides altering nectar nutrients, certain plant species alter pollinator behavior by producing nectar containing mildly toxic or narcotic chemicals. ${ }^{7}$
Consuming narcotic nectar can enhance pollination by altering the length of visits and encouraging pollinators to keep visiting that flower type.

\section{Other Resources}

Plants can provide additional nutritional resources such as food bodies, floral tissues, oils, and extrafloral nectaries for foraging pollinators or their offspring. ${ }^{3,4}$ In addition, plant structures can provide nesting materials or even a home itself. In one very specialized example, yucca moths stay inside Yucca plant flowers during the day and then pollinate them during the night. Some insects gain protection from predators by hiding in flowers, and certain predatory insects hunt for prey attracted to flowers. Others use flowers as meeting places; males pollinate while waiting for mates inside the flower. Insects can also use particular flowers as warm resting places. Bowl-shaped flowers can act as parabolic solar furnaces that entice the cold-blooded insect to visit and stay longer while providing the pollinator an energetic benefit. ${ }^{8}$

\section{Animal Pollinators-Honeybees Are Just the Start}

Pollination is performed by an extraordinary diversity of animals. On a global scale, 200,000 different animal species may act as pollinators for plants. ${ }^{9}$ This includes birds, bats, lizards, mice, and other small mammals. Vertebrates, however, make up less than $1 \%$ of species that pollinate. The real players are insects. This is true both worldwide and in rangelands where the following insects are the primary groups of pollinators.

\section{Honeybees}

Honeybees are the most visual and iconic pollinator and they make a tremendous contribution to many agricultural crops. These highly social insects collect pollen from many plant species, but they are less efficient than other species in pollinating certain crops and many native plants. ${ }^{10}$ In North America, humans keep only one species of honeybee, Apis mellifera (though there are many "breeds"), which was originally imported from Europe. Since honeybees can forage for pollen and nectar miles away from their colony, they are often important pollinators at the interface of agricultural systems and rangelands.

\section{Native Bees}

Unlike the nonnative honeybee, there are over 4,000 other bee species that are native to the United States. A few of them, such as the alfalfa leafcutting bee, are managed by humans to achieve particular pollination services. Many of the rest naturally play an important role in pollination, especially to native plants. A small number of native bees are social like honeybees, in that multiple individuals share a nest and there is some division of labor or shared resources. However, most are solitary nesters. For these species a single female creates a nest for her offspring and provisions it 
with the nectar and pollen she collects so that her flightless, grub-like offspring can develop into adults. Some native bees are generalists and visit a large number of plant species whereas others are specialized, using only certain plants. This specialization can help them be extremely effective pollinators of particular plants. For example, honeybees may be supergeneralists that can visit vast numbers of plant species, but they don't always "trip" specialized pollination mechanisms that are required for successful pollination. In lotus and locoweed in the western United States, honeybees often end up robbing nectar rather than helping the plants. Conversely, a native alkali bee can effectively pollinate up to 2,000 of these flowers in a day. ${ }^{9}$

\section{Moths and Butterflies}

Butterflies and moths are also common rangeland pollinators. Most adults feed extensively on nectar, with butterflies visiting flowers during the day and moths at night. For example, the California bay checkerspot butterfly is an endangered native species that thrives in range habitats and benefits from a well-managed livestock grazing regime. ${ }^{11}$ Monarch butterflies are migratory travelers that trek hundreds of miles on their journeys. They and other nomadic butterflies take up huge amounts of nectar to get the energy for their long flights, and in so doing end up being important pollinators in the southwestern United States and the Midwest's prairies. Closely related moths can also be important rangeland pollinators. Yucca plants in the southwestern United States need yucca moths to survive, and spurge hawk moths are crucial pollinators for an endangered prairie orchid (Travers et al., this issue).

\section{Other Pollinators}

There are many other insect pollinators in rangelands that receive less attention. Beetles were some of the first pollinators and still pollinate the vast majority of flowers worldwide, including native poppies in rangelands. ${ }^{12}$ Beetles often land on flowers and eat through both rewards and flower petals while pollinating. Sometimes called "mess and soil" pollinators, they are known for defecating within the flowers as they eat. In prairies, soldier beetles feed on and pollinate goldenrod flowers.

Other rangelands pollinators include flies such as those in colder climates where other pollinator species may be scarce and syrphids, which pollinate flowers as bee-looking adults and eat herbivorous pests such as aphids as juveniles. Wasps and ants can also pollinate native plants, but unlike the closely related bees, they are relatively inefficient since they tend to have less hair than bees and lack pollen-carrying structures. Other insects such as leafhoppers, walking sticks, and thrips are thought to pollinate various prairie plants.

\section{Pollination-Why is it So Complicated?}

We have tried to dispel the myth that pollination is simply honeybees flying from flower to flower, and instead establish that pollination is a multifaceted, complex relationship between an enormous diversity of plants and animals. This leads us to a central question: why is pollination so complicated?

We do not want to give the impression that there is a single, simple answer, but competition is an important driving factor for the complexity in pollination just as it is for the diversity of life. Both plants and pollinators are competing with other similar individuals; plants want pollinators to visit them and not others and a given pollinator wants to be the one to receive rewards. ${ }^{3}$ An organism can try to gain a competitive edge by being the absolute best at what it does. For example, it may produce the exact perfect nectar. However, another approach is to specialize.

The idea of specialization in pollination systems is that a plant has some specific set of characteristics that allows it to attract and use a specific group of pollinators, and these pollinators then do a very good job of pollinating that plant species. The traditional view is that pollination tends towards this specialization with pollinators and plants acting as "a lock and key." The Yucca-yucca moth system we've mentioned is an example in which a plant is only pollinated by a single pollinator species, which only pollinates that one plant. These examples, however, are merely one end of a continuum. On the other end, some plants are pollinated by hundreds of different animal species that can each pollinate many different plants. Rangeland areas have a mixture of specialist and generalist pollinator systems across this spectrum. Of the hundreds of native bee species in the Great Basin, approximately half are specialists in terms of the family of plants they visit, and the other half visit a broader array of plants. ${ }^{13}$ Similarly, in the Great Plains about a third are specialists and two-thirds generalists.

Below we outline a few of the ways plant flowers differ and how that affects their relationship with pollinators. Such differences are important for specialization and interacting with the right pollinators to maximize the benefits for both species.

\section{Flower Structure}

Flower shape can vary widely and is often important in pollination. ${ }^{4}$ Various flower shapes may exist to allow certain pollinators access while effectively forcing the pollinator to take up or deposit pollen. Certain flower shapes can thus be roughly correlated with their pollinators. For example, shallow flowers are often seen in bee-pollinated systems, whereas narrow nectar tubes are seen in moth- and butterfly-pollinated systems, and beetles pollinate large bowl-like flowers. These shapes may also be used in attracting pollinators.

\section{Flower Advertisements}

More commonly, flowers use color and fragrance to advertise their presence to potential pollinators. ${ }^{4}$ These advertisements help a flower compete for pollinators and potentially help pollinators learn to visit that type of flower. Advertisements are generally not of value themselves, although 
rewards such as ultraviolet-fluorescent nectar and yellow pollen may help with advertising. Even though we can simply characterize a flower's color apart from its scent, some pollinators may change their response to a color when they perceive a certain scent, thereby making it hard to disentangle the two.

Groups of pollinators are sometimes assigned "favorite" colors by determining what color flowers they visit most frequently, but some often visit flowers of many different colors. Since insect and human vision systems are different, figuring out these colors can be difficult unless we understand the wavelengths and colors the insects can see, the spectral reflectance of the flower, and whether the flower contrasts with its background. ${ }^{3,4}$ That being said, there is evidence that pollinators can use "color" in deciding what flowers to visit and even in ascertaining the flower's quality or age. ${ }^{3,4}$

Humans have long appreciated the various odors emanating from flowers, but the origin of those scents comes from pollinator attraction. Sweeping generalizations about odors are difficult since insects have varied abilities to pick up scents. Plants that bloom at night typically have a heavy and pervasive floral scent to attract moths from long distances. ${ }^{3}$ Meanwhile, plants that bloom in the day may use odors to help attract pollinators to land from a close range. As you might have expected by now, some plants use attractants to lure in pollinators without giving them nectar, pollen, or any other reward. There are different types of floral mimics in pollination including ones that mimic female insects to attract males to pollinate and others that take advantage of pollinators that have learned the cues of similar-looking, more abundant flowers that do offer rewards. ${ }^{4}$

\section{Conclusion}

The study of pollination has a long, rich history, but in many ways we have still only begun to understand the various facets of this important ecological interaction. This is particularly true for rangelands, wildlands, and native habitats. What is clear is that pollination plays a critical role in the reproduction of many rangeland plants and plant communities, and as such, it is an important ecological service in the rangeland ecosystem. As the following articles in this special issue will illustrate, there are a number of threats to this service, but there are also many opportunities for us as managers, scientists, and policy makers to ensure that pollination continues to contribute to the health and well-being of rangeland habitats.

\section{Acknowledgments}

The authors thank the two anonymous reviewers for their helpful comments and Lori Hidinger and the Rangelands Editorial Board for their help with this special issue of Rangelands and for making this article possible. We also thank The Xerces Society for Invertebrate Conservation,
USDA-Natural Resources Conservation Service West National Technical Support Center, and USDA-Forest Service for their financial assistance with this article.

\section{References}

1. National Research Council. 2007. Status of pollinators in North America. Washington, DC, USA: National Academic Press. 322 p.

2. Knight, T. M., J. A. Steets, J. C. Vamosi, S. J. Mazer, M. Burd, D. R. Campbell, M. R. Dudash, M. O. Johnston, R. J. Mitchell, and T. L. Ashman. 2005. Pollen limitation of plant reproduction: pattern and process. Annual Review of Ecology, Evolution, and Systematics 36:467-497.

3. Kevan, P. G., and H. G. Baker. 1983. Insects as flower visitors and pollinators. Annual Review of Entomology 28:407-453.

4. Dafni, A. 1992. Pollination ecology: a practical approach. Oxford, United Kingdom: Oxford University Press. 250 p.

5. Adams, D. E., W. E. Perkins, and J. R. Estes. 1981. Pollination systems in Paspalum dilatatum Poir. (Poaceae): an example of insect pollination in a temperate grass. American Journal of Botany 68:389-394.

6. Maloof, J. E., and D. W. Inouye. 2000. Are nectar robbers cheaters or mutualists? Ecology 81:2651-2661.

7. Jakubska, A., D. Przando, M. Steininger, J. AniolKwiatkowska, and M. Kadej. 2005. Why do pollinators become "sluggish"? Nectar chemical constituents from Epipactis helleborine (L.) Crantz (Orchidaceae). Applied Ecology and Environmental Research 3:29-38.

8. Norgate, M., S. Boyd-Gerny, V. Simonov, M. G. P. Rosa, T. A. Heard, and A. G. Dyer. 2010. Ambient temperature influences Australian native stingless bee Trigona carbonaria preference for warm nectar. PLOS ONE 5:e12000.

9. Buchmann, S. L., and G. P. Nabhan. 1996. The forgotten pollinators. Washington, DC, USA: Island Press. 186 p.

10. Kearns, C. A., and D. W. Inouye. 1997. Pollinators, flowering plants, and conservation. Bioscience 47:297-307.

11. Weiss, S. B. 1999. Cars, cows, and checkerspot butterflies: nitrogen deposition and management of nutrient-poor grasslands for a threatened species. Conservation Biology 13:1476-1486.

12. Schneider, E. L., ANd D. M. Nichols. 1984. Floral biology of Argemone aurantiaca (Papaveraceae). Bulletin of the Torrey Botanical Club 111:1-7.

13. Waser, N. M., L. Chittka, M. V. Price, N. M. Williams, and J. Ollerton. 1996. Generalization in pollination systems and why it matters. Ecology 77:1043-1060.

For additional readings on pollination and pollinators, see the on-line supplemental material at http://dx.doi.org/ 10.2111/RANGELANDS-D-11-00008.s1.

Authors are Assistant Professor, Entomology Dept, North Dakota State University, Fargo, ND 58108, USA, Jason.Harmon@ ndsu.edu (Harmon); Assistant Professor, Range Science Program, North Dakota State University, Fargo, ND 58108, USA (Ganguli); and Graduate Student, Range Science Program, North Dakota State University, Fargo, ND 58108, USA (Solga). 